\title{
Lipopolysaccharide-enhanced transcellular transport of HIV-1 across the blood-brain barrier is mediated by luminal microvessel IL- 6 and GM-CSF
}

\author{
Shinya Dohgu ${ }^{1,2,3}$, Melissa A Fleegal-DeMotta ${ }^{2,3,4}$ and William A Banks²,3,5,6*
}

\begin{abstract}
Elevated levels of cytokines/chemokines contribute to increased neuroinvasion of human immunodeficiency virus type 1 (HIV-1). Previous work showed that lipopolysaccharide (LPS), which is present in the plasma of patients with HIV-1, enhanced transcellular transport of HIV-1 across the blood-brain barrier (BBB) through the activation of p38 mitogen-activated protein kinase (MAPK) signaling in brain microvascular endothelial cells (BMECs). Here, we found that LPS (100 $\mathrm{gg} / \mathrm{mL}$, $4 \mathrm{hr}$ ) selectively increased interleukin (IL)-6 and granulocyte-macrophage colony-stimulating factor (GM-CSF) release from BMECs. The enhancement of HIV-1 transport induced by luminal LPS was neutralized by treatment with luminal, but not with abluminal, antibodies to IL-6 and GM-CSF without affecting paracellular permeability as measured by transendothelial electrical resistance (TEER). Luminal, but not abluminal, IL-6 or GMCSF also increased HIV-1 transport. U0126 (MAPK kinase (MEK)1/2 inhibitor) and SB203580 (p38 MAPK inhibitor) decreased the LPS-enhanced release of IL-6 and GM-CSF. These results show that p44/42 and p38 MAPK signaling pathways mediate the LPS-enhanced release of IL- 6 and GM-CSF. These cytokines, in turn, act at the luminal surface of the BMEC to enhance the transcellular transport of HIV-1 independently of actions on paracellular permeability.
\end{abstract}

Keywords: Blood-brain barrier, Human immunodeficiency virus type 1, Lipopolysaccharide, Interleukin-6, Granulocyte-macrophage colony-stimulating factor, Mitogen-activated protein kinase

\section{Background}

Human immunodeficiency virus type 1 (HIV-1) infection induces neurological dysfunctions known as the AIDS-dementia complex or HIV-associated dementia (HAD). Although highly active antiretroviral therapy (HAART) and combination antiretroviral therapy (cART) have dramatically decreased the incidence and severity of HAD, the prevalence of HAD, including minor cognitive and motor disorders, is increasing with the longer lifespan of HIV patients [1]. Most antiretroviral drugs comprising HAART have a restricted entry into the brain because of blood-brain barrier (BBB) efflux transporters so that the brain serves as a reservoir for HIV-1 [2] and a source for viral escape [3]. Therefore, HIV-1 in the brain can contribute to the incidence

\footnotetext{
* Correspondence: wabanks1@uw.edu

${ }^{2}$ Geriatric Research Educational and Clinical Center-St. Louis, St. Louis, MO, USA

Full list of author information is available at the end of the article
}

and development of HIV-associated neurological impairment in HIV-1 patients both prior to and after treatment with HAART/cART.

HIV-1 can enter the brain by two routes: the passage of cell-free virus by an adsorptive endocytosis-like mechanism [4-7] and trafficking of HIV-1-infected immune cells across the BBB [8]. HIV-1 infection of brain endothelial cells (BECs) is not a productive infection [9] and penetration of HIV-1 is independent of the CD4 receptor [10]. At the early stage, HIV-1 enters the brain through an intact, normally functioning $\mathrm{BBB}$ [11]. At later stages of infection, elevated levels of proinflammatory cytokines/chemokines in the blood of patients with AIDS [12-14] are likely associated with the increase in HIV-1 infiltration [15-17], while HIV-1 gp120 and Tat induce the disruption of tight junctions in BECs [17-20].

As reported by Brenchley et al. and confirmed by others, plasma levels of lipopolysaccharide (LPS), a
Ciomed Central

() 2011 Dohgu et al; licensee BioMed Central Ltd. This is an Open Access article distributed under the terms of the Creative Commons Attribution License (http://creativecommons.org/licenses/by/2.0), which permits unrestricted use, distribution, and reproduction in any medium, provided the original work is properly cited. 
Gram-negative bacterial endotoxin, are higher in chronic HIV-infected patients with HAART than in the uninfected $[3,21]$. Bacterial infection in HIV patients influences the severity and rate of disease progression [22]. Peripheral LPS induces various inflammatory and immunological reactions including the production of cytokines/chemokines, such as tumor necrosis factor- $\alpha$ (TNF- $\alpha$ interleukin (IL)-1, and IL-6 [23-25]. TNF- $\alpha$ enhances HIV-1 transport across the BBB [15] and LPS induces an increase in HIV-1-infected monocyte transport across the BBB [8]. In our previous in vivo study, we found that the peripheral injection of LPS enhanced gp120 uptake by brain [26]. These studies suggest that elevated levels of inflammatory mediators, including cytokines/chemokines and LPS, regulate the permeability of the BBB to HIV-1. BECs express LPS receptors, such as Toll-like receptor (TLR)-2, TLR-4, and CD14 [27] and are targets of LPS. The barrier function of the $\mathrm{BBB}$ is affected by various cytokines/chemokines in the blood compartment [28]. Several studies using in vitro BBB models have shown that LPS increases the paracellular permeability of the BBB [29-33]. LPS induces or enhances the secretion of several cytokines by BECs [34]. Thus, bacterial infection and the accompanying inflammatory state could be involved in the enhancement of HIV-1 entry into the brain.

We recently reported that LPS increased transcellular transport of HIV-1 across the BBB through p38 mitogen-activated protein kinase (MAPK) [35]. Here, we examined whether LPS-enhanced release of cytokines by BMECs mediated the transcellular transport of HIV-1 and was regulated by MAPK signaling pathways.

\section{Materials and methods}

\section{Radioactive labeling}

HIV-1 (MN) CL4/CEMX174 (T1) prepared and rendered noninfective by aldrithiol-2 treatment as previously described [36] was a kind gift of the National Cancer Institute, NIH. The virus was radioactively labeled by the chloramine- $\mathrm{T}$ method, a method which preserves vial coat glycoprotein activity [37,38]. Two $\mathrm{mCi}$ of ${ }^{131} \mathrm{I}-\mathrm{Na}$ (Perkin Elmer, Boston, MA), $10 \mu \mathrm{g}$ of chloramine- $\mathrm{T}$ (Sigma) and $5.0 \mu \mathrm{g}$ of the virus were incubated together for $60 \mathrm{sec}$. The radioactively labeled virus was purified on a column of Sephadex G-10 (Sigma).

\section{Primary culture of mouse brain microvascular endothelial cells (BMECs)}

BMECs were isolated by a modified method of Szabó et al. [39] and Nakagawa et al. [38]. The animals were housed in clean cages in the laboratory with free access to food and water and were maintained on a 12-h dark, 12-h light cycle in a room with controlled temperature $\left(24 \pm 1^{\circ} \mathrm{C}\right)$ and humidity $(55 \pm 5 \%)$. All procedures involving experimental animals were approved by the local Animal Care and Use Committee and were performed in a facility approved by Association for Assessment and Accreditation of Laboratory Animal Care. Cerebral cortices harvested from 8-week-old male CD-1 mice from our in-house colony were homogenized, BMECs extracted, and cultured as previously performed [40]. Cultures were treated with puromycin to remove pericytes.

\section{Preparation of in vitro BBB models}

BMECs $\left(4 \times 10^{4}\right.$ cells/well) were seeded on the inside of the fibronectin-collagen IV $(0.1$ and $0.5 \mathrm{mg} / \mathrm{mL}$, respectively)-coated polyester membrane $\left(0.33 \mathrm{~cm}^{2}, 0.4 \mu \mathrm{m}\right.$ pore size) of a Transwell ${ }^{\circledR}$-Clear insert (Costar, Corning, NY) placed in the well of a 24-well culture plate (Costar). Culture methods were the same as previously reported [35]. Transendothelial electrical resistance (TEER in $\Omega \times \mathrm{cm}^{2}$ ) was measured before the experiments and after an exposure of LPS using an EVOM voltohmmeter equipped with STX-2 electrode (World Precision Instruments, Sarasota, FL). The TEER of cellfree Transwell ${ }^{\circledR}$-Clear inserts were subtracted from the obtained values.

\section{Pretreatment protocol}

Lipopolysaccharide from Salmonella typhimurium (LPS; Sigma), monoclonal anti-mouse GM-CSF antibody, antimouse IL-6 antibody, mouse GM-CSF, and mouse IL-6 (all purchased from R\&D systems, Minneapolis, MN) were dissolved in serum-free DMEM/F-12 (DMEM/F-12 containing $1 \mathrm{ng} / \mathrm{mL}$ bFGF and $500 \mathrm{nM}$ hydrocortisone). The dose of LPS used in previous BMEC studies (100 $\mu \mathrm{g} / \mathrm{mL}$ ) was added to the luminal chamber of the Transwell $^{\circledR}$ inserts, and anti-mouse GM-CSF antibody $(10 \mu \mathrm{g} /$ $\mathrm{mL})$, anti-mouse IL- 6 antibody $(10 \mu \mathrm{g} / \mathrm{mL})$, mouse GMCSF (1-100 $\mathrm{ng} / \mathrm{mL})$, or mouse IL-6 (1-100 $\mathrm{ng} / \mathrm{mL})$ was loaded into the luminal or abluminal chamber. Then, the BMEC monolayers were incubated for $4 \mathrm{hr}$ at $37^{\circ} \mathrm{C}$ with a humidified atmosphere of $5 \% \mathrm{CO}_{2} / 95 \%$ air. In the experiments using antibodies, rat IgG (Sigma) was added to the control and LPS-treated group $(10 \mu \mathrm{g} / \mathrm{mL}$ as final concentration).

U0126 (MEK inhibitor; Tocris Cookson Inc., Ellisville, MO), SB203850 (p38 MAPK inhibitor; Tocris) and SP600125 (Jun kinase (JNK) inhibitor; Sigma) were first dissolved in dimethyl sulfoxide (DMSO) and diluted with serum-free DMEM/F-12 (0.1\% as the final DMSO concentration).

\section{Transendothelial transport of ${ }^{131} \mathrm{I}$-HIV-1}

For the transport experiments, the medium was removed and BMECs were washed with physiological buffer containing $1 \%$ BSA $(141 \mathrm{mM} \mathrm{NaCl}, 4.0 \mathrm{mM} \mathrm{KCl}$, 
$2.8 \mathrm{mM} \mathrm{CaCl}_{2}, 1.0 \mathrm{mM} \mathrm{MgSO} 4,1.0 \mathrm{mM} \mathrm{NaH}_{2} \mathrm{PO}_{4}, 10$ mM HEPES, $10 \mathrm{mM}$ D-glucose and 1\% BSA, pH 7.4). The physiological buffer containing 1\% BSA was added to the outside (abluminal chamber; $0.6 \mathrm{~mL}$ ) of the Transwell ${ }^{\circledR}$ insert. To initiate the transport experiments, ${ }^{131}$ I-HIV-1 $\left(3 \times 10^{6} \mathrm{cpm} / \mathrm{mL}\right)$ was loaded on the luminal chamber. The side opposite to that to which the radioactive materials were loaded is the collecting chamber. Samples $(0.5 \mathrm{ml})$ were removed from the abluminal chamber at 15, 30, 60 and $90 \mathrm{~min}$ and immediately replaced with an equal volume of fresh $1 \%$ BSA/physiological buffer. All samples were mixed with $30 \%$ trichloroacetic acid (TCA; final concentration 15\%) and centrifuged at $5,400 \times \mathrm{g}$ for $15 \mathrm{~min}$ at $4^{\circ} \mathrm{C}$. Radioactivity in the TCA precipitate was determined in a gamma counter. The permeability coefficient and clearance of TCA-precipitable 131I-HIV-1 was calculated according to the method described by Dehouck et al. [41]. Clearance was expressed as microliters $(\mu \mathrm{L})$ of radioactive tracer diffusing from the luminal to abluminal (influx) chamber and was calculated from the initial level of radioactivity in the loading chamber and final level of radioactivity in the collecting chamber:

$$
\text { Clearance }(\mu \mathrm{L})=[\mathrm{C}]_{\mathrm{C}} \times V_{\mathrm{C}} /[\mathrm{C}]_{\mathrm{L}}
$$

where $[C]_{L}$ is the initial radioactivity in a microliter of loading chamber (in $\mathrm{cpm} / \mu \mathrm{L}$ ), $[\mathrm{C}]_{\mathrm{C}}$ is the radioactivity in a microliter of collecting chamber (in $\mathrm{cpm} / \mu \mathrm{L}$ ), and $V_{\mathrm{C}}$ is the volume of collecting chamber (in $\mu \mathrm{L}$ ). During a 90-min period of the experiment, the clearance volume increased linearly with time. The volume cleared was plotted versus time, and the slope was estimated by linear regression analysis. The slope of clearance curves for the BMEC monolayer plus Transwell ${ }^{\circledR}$ membrane was denoted by $P S_{\text {app }}$, where $P S$ is the permeability $\times$ surface area product (in $\mu \mathrm{L} / \mathrm{min}$ ). The slope of the clearance curve with a Transwell ${ }^{\mathbb{R}}$ membrane without BMECs was denoted by $P S_{\text {membrane. The real } P S \text { value }}$ for the BMEC monolayer $\left(P S_{\mathrm{e}}\right)$ was calculated from

$$
1 / P S_{\text {app }}=1 / P S_{\text {membrane }}+1 / P S_{e} \text {. }
$$

The $P S_{\mathrm{e}}$ values were divided by the surface area of the Transwell ${ }^{\mathbb{B}}$ inserts $\left(0.33 \mathrm{~cm}^{2}\right)$ to generate the endothelial permeability coefficient $\left(P_{\mathrm{e}}\right.$, in $\left.\mathrm{cm} / \mathrm{min}\right)$.

\section{Cytokine detection}

BMECs $\left(4 \times 10^{4}\right.$ cells/well $)$ were seeded on the fibronectin/collagen I/collagen IV $(0.05,0.05$, and $0.1 \mathrm{mg} / \mathrm{mL}$, respectively)-coated 24-well culture plate (Costar). BMECs were washed with serum-free DMEM/F-12, and then exposed to $200 \mu \mathrm{L}$ of LPS $(100 \mu \mathrm{g} / \mathrm{mL})$ with or without U0126 $(10 \mu \mathrm{M})$, SB203580 $(10 \mu \mathrm{M})$, and SP600125 $(10 \mu \mathrm{M})$ for $4 \mathrm{hr}$ at $37^{\circ} \mathrm{C}$. Culture supernatant was collected and stored at $-80^{\circ} \mathrm{C}$ until use. The cytokines (GM-CSF, IFN- $\gamma$, IL-1 $\alpha$, IL-1 $\beta$, IL-2, IL-4, IL-6, IL-10, IL-12 (p70), and TNF- $\alpha$ ) were measured with the mouse cytokine/chemokine Lincoplex ${ }^{\circledR}$ kit (Linco Research, St. Charles, MO) by following the manufacturer's instructions.

\section{Western blot analysis}

LPS, GM-CSF, or IL-6-treated and control BMECs were washed three times with ice-cold phosphate buffered saline containing $1 \mathrm{mM}$ sodium orthovanadate $\left(\mathrm{Na}_{3} \mathrm{VO}_{4}\right)$ and $1 \mathrm{mM}$ sodium fluoride $(\mathrm{NaF})$. Cells were scraped and lysed in phosphoprotein lysis buffer (10 mM Tris- $\mathrm{HCl}, \mathrm{pH} 6.8,100 \mathrm{mM} \mathrm{NaCl}, 1 \mathrm{mM}$ EDTA, 1 mM EGTA, 10\% glycerol, 1\% Triton X-100, 0.1\% SDS, $0.5 \%$ sodium deoxycholate, $20 \mathrm{mM}$ sodium pyrophosphate decahydrate, $2 \mathrm{mM} \mathrm{Na}_{3} \mathrm{VO}_{4}, 1 \mathrm{mM} \mathrm{NaF}, 1 \mathrm{mM}$ phenylmethylsulfonyl fluoride) containing $1 \%$ protease inhibitor cocktail (Sigma) on ice. Cell lysates were centrifuged $\left(15,000 \times \mathrm{g}\right.$ at $4^{\circ} \mathrm{C}$ for $\left.15 \mathrm{~min}\right)$ and the supernatants were stored at $-80^{\circ} \mathrm{C}$ until use. The protein concentration of each sample was determined using a BCA protein assay kit (Pierce, Rockford, IL). Twenty to thirty $\mu \mathrm{g}$ of the total protein was mixed with NuPAGE ${ }^{\mathbb{R}}$ LDS sample buffer (Invitrogen) and incubated for $3 \mathrm{~min}$ at $100^{\circ} \mathrm{C}$. Proteins were separated on NuPAGE ${ }^{\circledR}$ Novex 4-12\% Bis-Tris gel (Invitrogen) and then transferred to a polyvinylidene difluoride (PVDF) membrane (Invitrogen). After transfer, the blots were blocked with 5\% BSA/Tris-buffered saline (TBS: $20 \mathrm{mM}$ Tris- $\mathrm{HCl}, \mathrm{pH}$ 7.5, $150 \mathrm{mM} \mathrm{NaCl}$ ) containing $0.05 \%$ Tween 20 (TBS-T) for $1 \mathrm{hr}$ at room temperature. The membrane was incubated with the primary antibody diluted in 5\% BSA/ TBS-T overnight at $4^{\circ} \mathrm{C}$. The phosphorylation of $\mathrm{p} 44 / 42$ MAPK, p38 MAPK and JNK were detected using antiphospho-p44/42 MAPK (1:1000), anti-phospho-p38 MAPK (1:500) and anti-phospho-JNK (1:500) rabbit monoclonal antibodies, respectively (all purchased from Cell Signaling Technology, Beverly, MA). Occludin, claudin-5, and ZO-1 were detected using anti-occludin, anti-claudin-5, and anti-ZO-1 mouse monoclonal antibodies (all purchased from Zymed, South San Francisco, CA). Blots were washed and incubated with horseradish peroxidase-conjugated anti-mouse IgG or anti-rabbit IgG (1:10, 000; Santa Cruz Biotechnology, Santa Cruz, CA) diluted in 5\% BSA/TBS-T for $1 \mathrm{hr}$ at room temperature. The immunoreactive bands were visualized on an X-ray film (Kodak) using SuperSignal ${ }^{\circledR}$ West Pico chemiluminescent substrate kit (Pierce). To reprobe total p44/42 MAPK, p38 MAPK, JNK, and actin, the membrane was incubated in stripping buffer $(0.2 \mathrm{M}$ glycine, $0.1 \%$ SDS and $1 \%$ Tween 20, pH 2.2) for $15 \mathrm{~min}$ twice and blocked with $5 \%$ non-fat dry milk/TBS-T. The total p44/42 MAPK, p38 MAPK and JNK were detected 
using anti-p44/42 MAPK (1:1000), p38 MAPK (1:1000), JNK (1:1000) (all purchased from Cell Signaling Technology), and actin (1:1000; Santa Cruz Biotechnology) antibodies, respectively. To quantify the relative levels of protein expression, the intensity of specific protein bands was quantified using ImageJ software (National Institute of Health, Bethesda, MD) and then normalized by that of each loading control protein.

\section{Statistical analysis}

Values are expressed as means \pm SEM. One-way and two-way analysis of variances (ANOVAs) followed by Dunnett's or Tukey-Kramer's test were applied to multiple comparisons. Paired t-test was applied to the densitometry analysis. The differences between means were considered to be significant when $P$ values were less than 0.05 using Prism 5.0 (GraphPad, San Diego, CA).

\section{Results}

LPS stimulated release of GM-CSF and IL- 6 by BMEC

As shown in Table 1, BMECs spontaneously secreted IL-1 $\beta$, IL-2, IL-4, IL-10, IL-12, and TNF- $\alpha$ in the 0.5-2.5 $\mathrm{pg} / \mathrm{mL}$ range, and GM-CSF, IFN- $\gamma$, and IL- 6 in 4-7 pg/ $\mathrm{mL}$ range in this study. The concentration of IL- $1 \alpha$ was below the detection level of the assay. A $4 \mathrm{hr}$ exposure of BMECs to LPS $(100 \mu \mathrm{g} / \mathrm{mL})$ significantly induced 33and 2.4-fold increases in the levels of GM-CSF and IL-6, respectively $(P<0.01)$. LPS significantly decreased the secretion of IFN- $\gamma$ by BMECs $(P<0.01)$, but the decrease in the secretion of IL-12 with LPS did not reach statistical significance. Secretion of IL-1 $\beta$, IL-2, and IL-10 was not detected after LPS treatment. The level of IL- 4 and TNF- $\alpha$ did not change after LPS treatment.

Table 1 Effect of LPS on the release of cytokines by BMECs.

\begin{tabular}{lcc}
\hline & \multicolumn{2}{c}{ Treatment } \\
\cline { 2 - 3 } Cytokine $(\mathbf{p g} / \mathbf{m L})$ & Control & LPS $\mathbf{1 0 0} \mathbf{\mu g} / \mathbf{m L}$ \\
\hline GM-CSF & $4.8 \pm 3.1$ & $160.0 \pm 21.7^{* *}$ \\
IFN- $\gamma$ & $4.4 \pm 1.1$ & $1.6 \pm 0.6^{*}$ \\
IL-1 $\alpha$ & N.D. & N.D. \\
IL-1 $\beta$ & N.D. & N.D. \\
IL-2 & $1.1 \pm 0.5$ & N.D. \\
IL-4 & $0.9 \pm 0.2$ & $0.5 \pm 0.2$ \\
IL-6 & $6.7 \pm 1.1$ & $16.3 \pm 2.3^{* *}$ \\
IL-10 & $2.3 \pm 1.1$ & N.D. \\
IL-12 (p70) & $1.6 \pm 0.6$ & $0.3 \pm 0.3$ \\
TNF- $\alpha$ & $0.5 \pm 0.3$ & $0.2 \pm 0.2$ \\
\hline
\end{tabular}

BMECs were exposed to LPS $(100 \mu \mathrm{g} / \mathrm{mL})$ for $4 \mathrm{hr}$. Mean \pm SEM $(n=7)$. N.D.: Not Detected. Statistical analysis was done by Student's t-test. ${ }^{*} P<0.05$, ${ }^{* *} P$ $<0.01$ vs control.
Polarized effect of antibodies to IL- 6 and GM-CSF on LPSinduced increase in HIV-1 permeability and paracellular permeability of BMEC monolayer

To examine whether the enhanced release of IL- 6 and GM-CSF induced by LPS was involved in the LPSinduced increases in HIV-1 permeability and paracellular permeability of the BMEC monolayer, we exposed BMEC monolayers to LPS with antibodies to IL-6 and GM-CSF. Since BMECs can release cytokines from either their luminal or abluminal surface [34], we examined the functional polarity of antibodies to IL- 6 and GM-CSF by adding them into the luminal or abluminal chambers. We assessed the paracellular permeability of the BMEC monolayer by measuring TEER. LPS $(100 \mu \mathrm{g} /$ $\mathrm{mL}$ for $4 \mathrm{hr}$ ) added to the luminal chamber significantly increased ${ }^{131}$ I-HIV-1 permeability of BMEC monolayers (Figure $1 \mathrm{~A}$ and $1 \mathrm{C}$ ) and decreased TEER (Figure 1B and 1D). The presence of antibodies to IL-6 and GM-CSF $(10 \mu \mathrm{g} / \mathrm{mL}$, respectively) in the luminal chamber significantly attenuated the LPS-induced increase in ${ }^{131}$ I-HIV1 (Figure 1A), but not the LPS-induced decrease in TEER (Figure 1B). In contrast, antibodies added into the abluminal chamber did not inhibit the LPS-induced increase in ${ }^{131}$ I-HIV-1 permeability and the decrease in TEER (Figure 1C and 1D).

\section{Polarized response to IL- 6 and GM-CSF in the permeability of BMEC monolayer}

To determine whether IL- 6 and GM-CSF mediate HIV-1 transport across the BBB and decrease TEER with the functional polarity, BMECs were treated with various concentrations of mouse IL-6 and GM-CSF (1-100 ng/ $\mathrm{mL}$, respectively) in the luminal or abluminal chamber. In Figure 2A, luminal treatment with IL-6 $(1,10$, and 100 $\mathrm{ng} / \mathrm{mL}$ ) increased HIV-1 transport to $104.6 \pm 6.8,121.9 \pm$ 5.4 , and $127.9 \pm 4.1 \%$ of control, but abluminal treatment did not induce significant changes in HIV-1 transport $(96.5 \pm 3.2,110.2 \pm 3.6$, and $99.6 \pm 5.0 \%$ of control $)$. Luminal treatment with IL-6 $(1,10$, and $100 \mathrm{ng} / \mathrm{mL})$ significantly decreased TEER (Figure $2 \mathrm{~B}$ ) from $72.1 \pm 1.2$ to $64.2 \pm 2.8,58.3 \pm 2.0$, and $56.4 \pm 1.4 \Omega \times \mathrm{cm}^{2}$. Abluminal treatment with IL- 6 significantly decreased TEER from $72.0 \pm 2.0$ to $58.9 \pm 2.7 \Omega \times \mathrm{cm}^{2}$ at the concentration of $100 \mathrm{ng} / \mathrm{mL}$. For the permeability to HIV-1 (Figure 2A), a two-way ANOVA showed significant effects for the factors "loading chamber" (luminal or abluminal) $[F(1,67)=$ 11.42, $P<0.01]$, concentration $[F(3,67)=5.715, P<$ $0.01]$, and interaction (loading chamber $\times$ concentration) $[F(3,67)=2.788, P<0.05]$. For TEER (Figure $2 \mathrm{~B}$ ), a twoway ANOVA showed a significant effect for concentration $[F(3,58)=10.08, P<0.001]$, but not for loading chamber and interaction.

As shown in Figure 3A, GM-CSF $(1,10,100 \mathrm{ng} / \mathrm{mL})$ in the luminal chamber increased HIV-1 transport to 


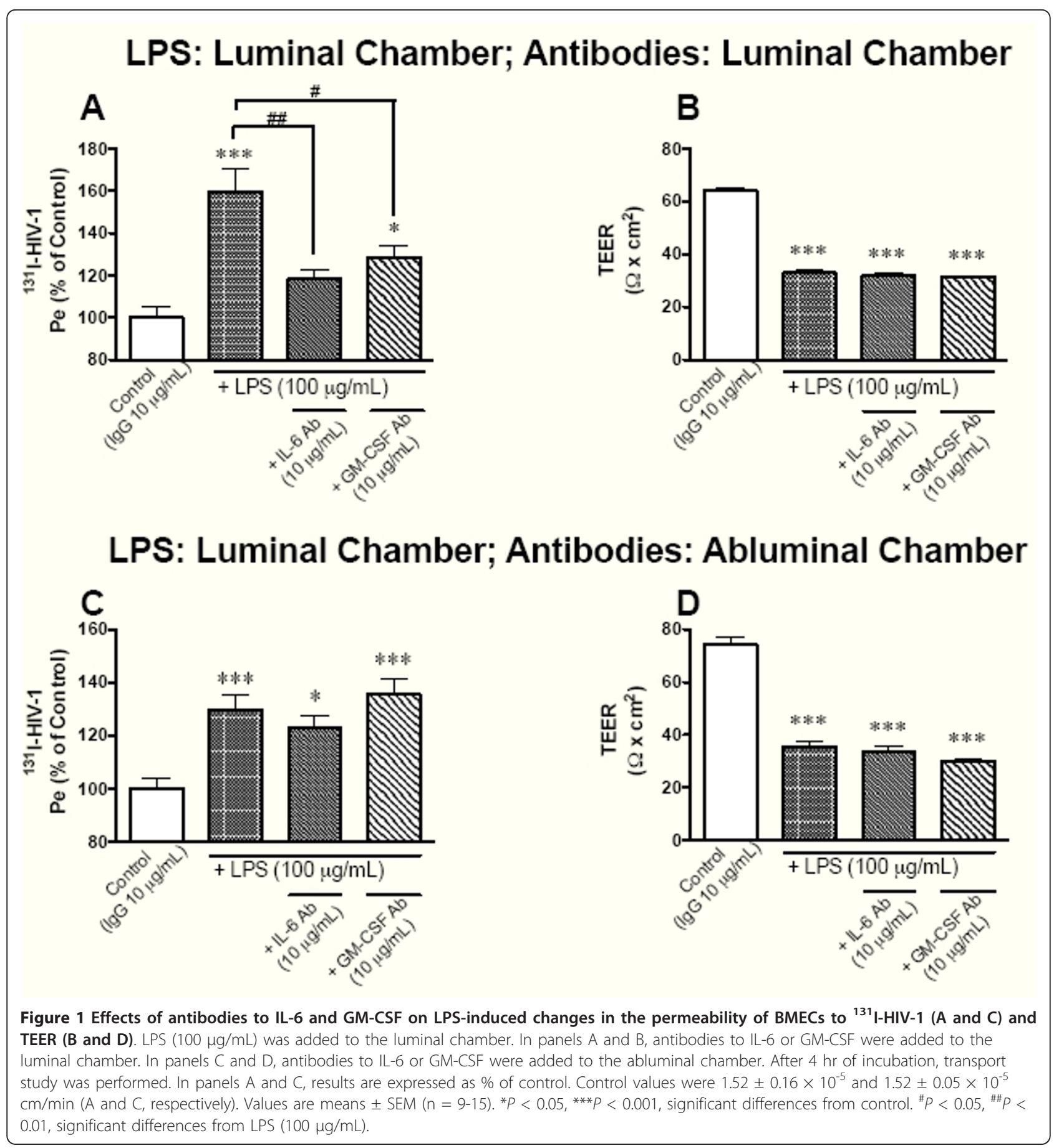

$103.6 \pm 3.4,107.0 \pm 5.4$, and $124.0 \pm 5.1 \%$ of control, but GM-CSF in the abluminal chamber did not $(101.8 \pm 5.1$, $94.5 \pm 3.9$, and $95.4 \pm 5.2 \%$ of control). Neither the luminal nor abluminal treatments with GM-CSF changed TEER (Figure 3B). For the permeability to HIV-1 (Figure 3A), a two-way ANOVA showed significant effects for loading chamber $[F(1,44)=7.746, P<0.01]$ and interaction $[F(3,44)=2.909, P<0.01]$ but not concentration.
For TEER (Figure 3B), a two-way ANOVA showed a significant effect for loading chamber $[F(1,74)=4.682, P<$ $0.05]$ but not concentration or interaction.

These results indicated that the effects of LPS on BMECs permeability to HIV-1 were mainly mediated by IL-6 and GM-CSF acting at the luminal surface of the BMEC. In all subsequent studies, therefore, we employed the luminal chamber as the loading chamber. 

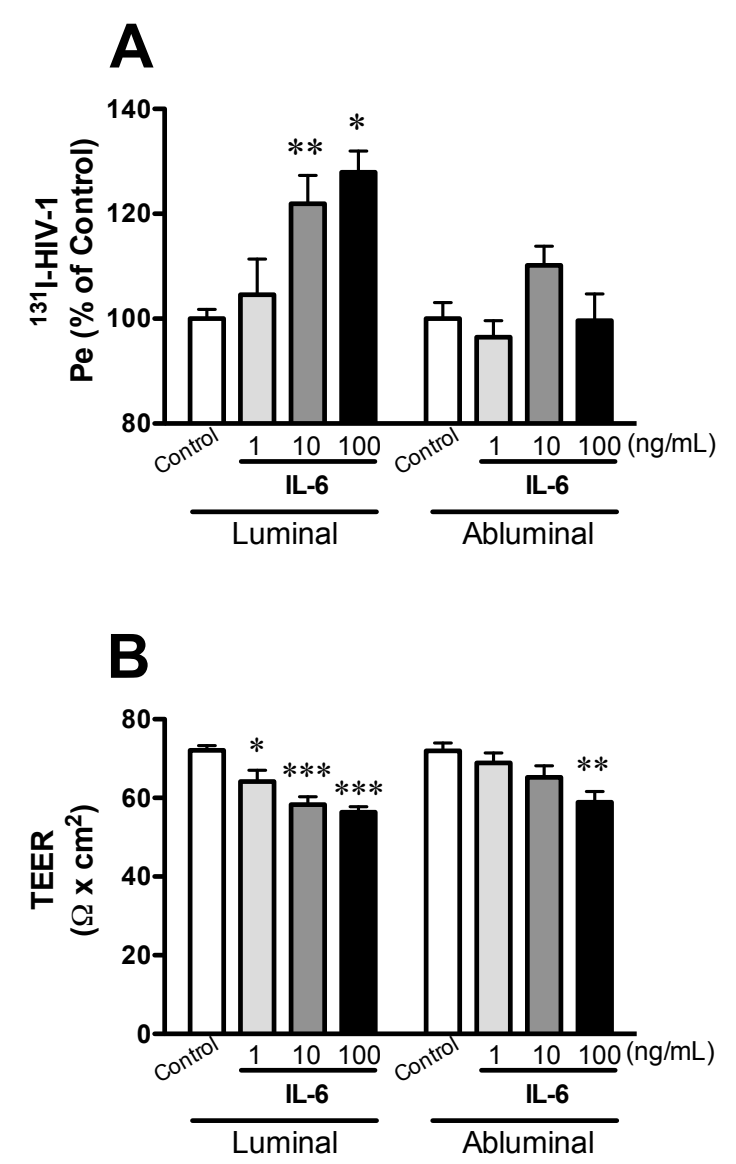

Figure 2 Functional polarity to IL- 6 in BMEC permeability of HIV-1 (A) and TEER (B). BMECs were exposed to IL-6 (1, 10, and $100 \mathrm{ng} / \mathrm{mL}$ ) in the luminal or abluminal chamber for $4 \mathrm{hr}$. In panel A, results are expressed as \% of control. The control values of permeability coefficient for ${ }^{131} \mathrm{I}-\mathrm{HIV}$ - 1 in panel A was $1.03 \pm 0.11 \times$ $10^{-5}$ and $1.07 \pm 0.08 \times 10^{-5} \mathrm{~cm} / \mathrm{min}$ for the luminal and abluminal control, respectively. Values are means \pm SEM $(n=3-12) .{ }^{*} P<0.05$, ${ }^{*} P<0.01,{ }^{* * *} P<0.001$, significant difference from each corresponding control.

Effects of LPS, IL-6, and GM-CSF on the expression of tight junction proteins

To examine the effects of LPS, IL-6, and GM-CSF on the expression of tight junction proteins, BMECs were exposed to LPS $(100 \mu \mathrm{g} / \mathrm{mL})$, IL-6 (100 ng/mL), and GM-CSF (100 ng/mL) for $4 \mathrm{hr}$ (Figure 4$)$. The densitometry analysis showed that there were no significant changes in the expression of tight junction proteins induced by LPS, IL-6, and GM-CSF.

Effect of MAPK inhibitors on the release of IL-6 and GMCSF enhanced by LPS

We previously demonstrated that LPS activated p44/42 MAPK and p38 MAPK pathways in BMECs [35]. To
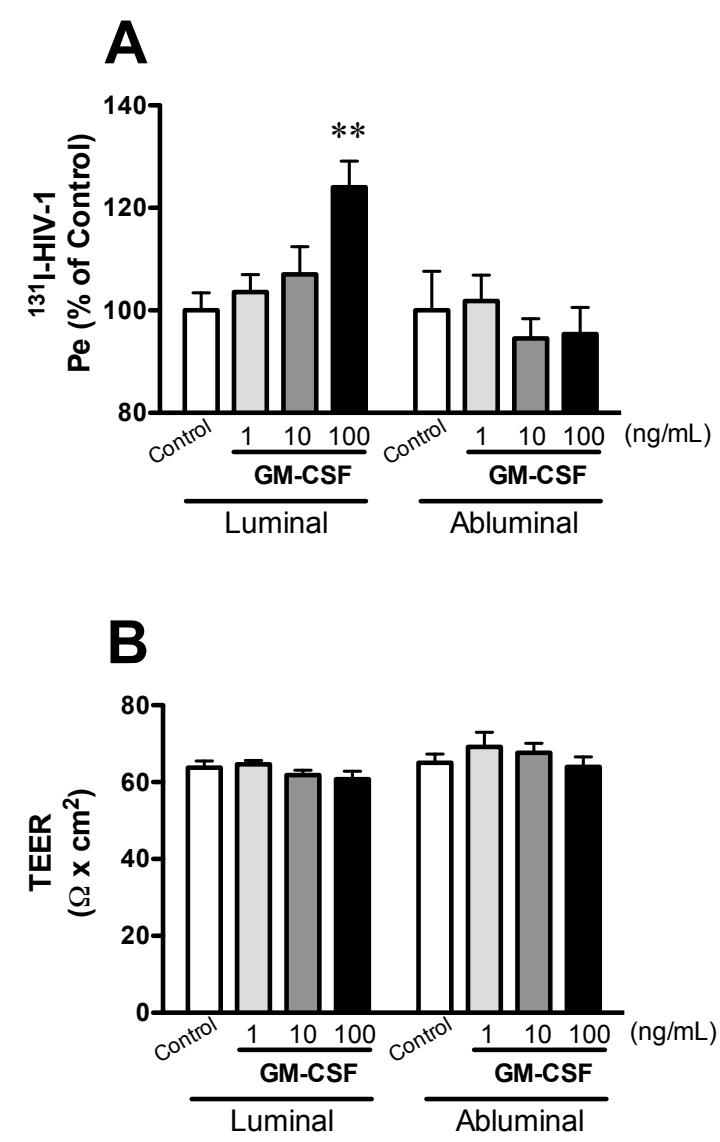

Figure 3 Functional polarity to GM-CSF in BMEC permeability of HIV-1 (A) and TEER (B). BMECs were exposed to GM-CSF (1, 10, and $100 \mathrm{ng} / \mathrm{mL}$ ) in the luminal or abluminal chamber for $4 \mathrm{hr}$. In panel A, results are expressed as $\%$ of control. The control values of permeability coefficient for ${ }^{131} \mathrm{I}-\mathrm{HIV}$ - 1 in panel A was $137 \pm 0.13 \times$ $10^{-5}$ and $1.32 \pm 0.13 \times 10^{-5} \mathrm{~cm} / \mathrm{min}$ for the luminal and abluminal control, respectively. Values are means $\pm \operatorname{SEM}(n=3-12) .{ }^{* *} P<0.01$, significant difference from control.

test whether LPS enhances the release of IL-6 and GMCSF by BMECs through MAPK signaling pathways, BMECs were exposed to LPS with various MAPK inhibitors (U0126, SB203580, and SP600125) for 4 hr. As shown in Figure 5A and 5B, LPS significantly enhanced the release of IL- 6 and GM-CSF by BMECs from $1.7 \pm$ 0.71 to $35.5 \pm 10.5 \mathrm{pg} / \mathrm{mL}(P<0.01)$ and from $7.8 \pm 7.8$ to $261.4 \pm 25.7 \mathrm{pg} / \mathrm{mL}(P<0.001)$, respectively. In the presence of $10 \mu \mathrm{M}$ of U0126 (MEK1/2 inhibitor), the LPS-induced increase in the release of IL- 6 and GMCSF by BMECs was significantly decreased to $13.0 \pm 2.1$ $(P<0.05$ vs LPS $)$ and $199.0 \pm 16.0 \mathrm{pg} / \mathrm{mL}(P<0.05$ vs LPS), respectively. Similarly, SB203580 (10 $\mu \mathrm{M}:$ p38 MAPK inhibitor) significantly decreased the LPSenhanced release of IL- 6 and GM-CSF by BMECs to 

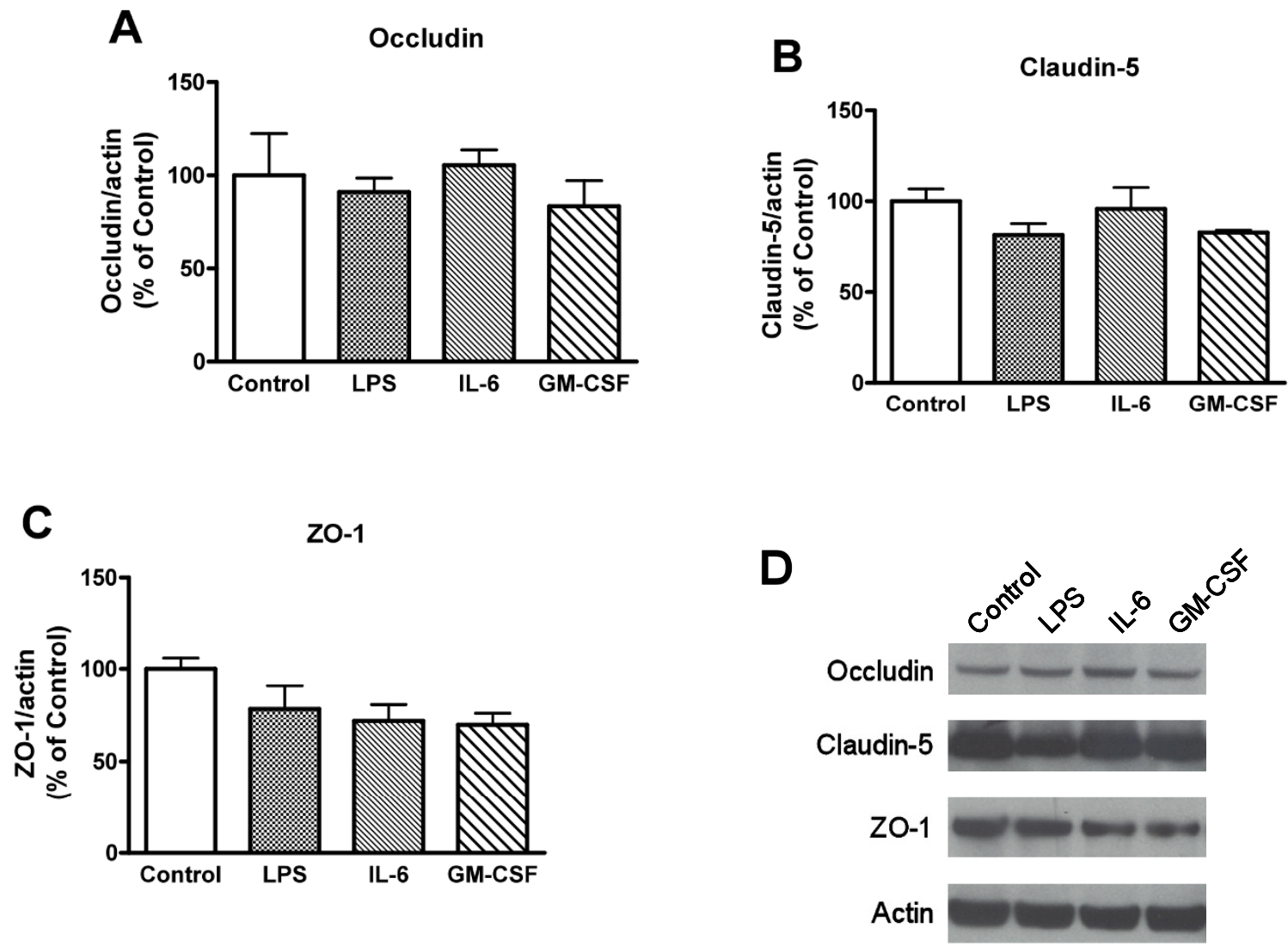

Figure 4 Effects of LPS, IL-6, and GM-CSF on the expression of tight junction proteins in BMECs. BMECs were exposed to LPS (100 $\mu \mathrm{g} /$ $\mathrm{mL}), \mathrm{IL}-6(100 \mathrm{ng} / \mathrm{mL})$, or GM-CSF (100 ng/mL) for $4 \mathrm{hr}$. Expression levels of occludin, claudin-5, ZO-1, and actin were detected by western blot. Relative intensity of occludin (A), claudin-5 (B), and ZO-1 (C) is calculated as ratio of arbitrary densitometric units of target protein to that of actin. Results are expressed \% of control. Values are means \pm SEM $(n=3)$. (D) Photographs are representative in three independent experiments.

$14.9 \pm 3.1(P<0.05$ vs LPS $)$ and $139.9 \pm 10.8 \mathrm{pg} / \mathrm{mL}(P$ $<0.01$ vs LPS). The JNK inhibitor SP600125 $(10 \mu \mathrm{M})$ did not affect the LPS-enhanced release of IL- 6 and GM-CSF.

\section{Effects of IL- 6 and GM-CSF on phosphorylation of p44/42} MAPK, p38, and JNK

To determine whether IL- 6 and GM-CSF could activate MAPK pathways in BMECs as in the case of LPS phosphorylation of MAPKs were measured by western blot analysis (Figure 6). A $4 \mathrm{hr}$ exposure of BMECs to IL-6 (100 $\mathrm{ng} / \mathrm{mL})$ or GM-CSF $(100 \mathrm{ng} / \mathrm{mL})$ in the luminal side did not increase the phosphorylation of $\mathrm{p} 44 / 42$ MAPK, p38, or JNK.

\section{Discussion}

The present study evaluated whether the LPS-enhanced transcellular transport of HIV-1 across BMEC monolayers was mediated through the induction of the release of cytokines from BMECs. Our main findings are summarized in Figure 7. BMECs spontaneously secreted GM-CSF, IFN- $\gamma$, IL-2, IL-4, IL-6, and TNF- $\alpha$ (Table 1) with relatively high concentrations $(>4 \mathrm{pg} / \mathrm{mL})$ of IL-6, GM-CSF, and IFN- $\gamma$. LPS markedly increased the concentrations of IL- 6 and GM-CSF. Therefore, we hypothesized that IL- 6 and/or GM-CSF might mediate the LPS-induced increase in HIV-1 transport across the BBB. Previously, we showed that BMECs in which pericytes were not removed spontaneously secrete GM-CSF, IL-1 $\alpha$, IL-6, IL-10, and TNF- $\alpha$ and that LPS stimulates the secretion of GM-CSF, IL-6, IL-10, and TNF- $\alpha$ [34]. In the current study, the LPS-induced increase in IL-10 and TNF- $\alpha$ secretion was not observed. This may be attributed to the differences of culture conditions, such as the use of culture medium containing hydrocortisone, absence of pericytes, or differences among batches of LPS. Although hydrocortisone inhibits the production of TNF- $\alpha$ by LPS-stimulated monocytes [42], the 


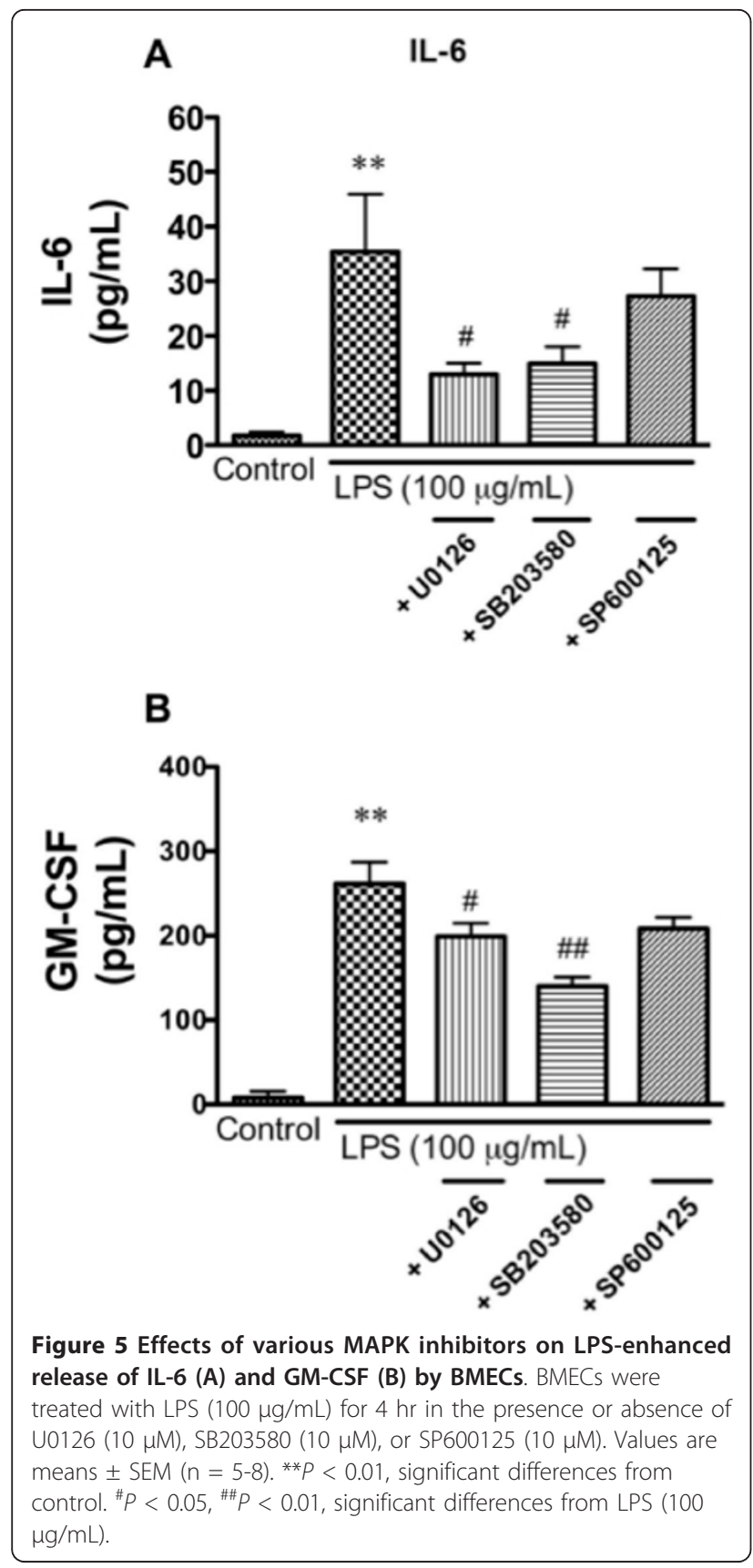

concentration of hydrocortisone that we used was at a physiological level [43].

BBB disruption can occur either [44] through the paracellular route (increased leakage between cells as measured by a decrease in TEER) or though the transcellular route (increased passage across a cell). Viralsized particles [45], including HIV-1 [7], generally cross by the transcellular route. Our previous work found that LPS both increased the transcellular permeability of the BMEC monolayer to HIV-1 and decreased TEER [35]. Here, we examined whether IL-6 and GM-CSF release

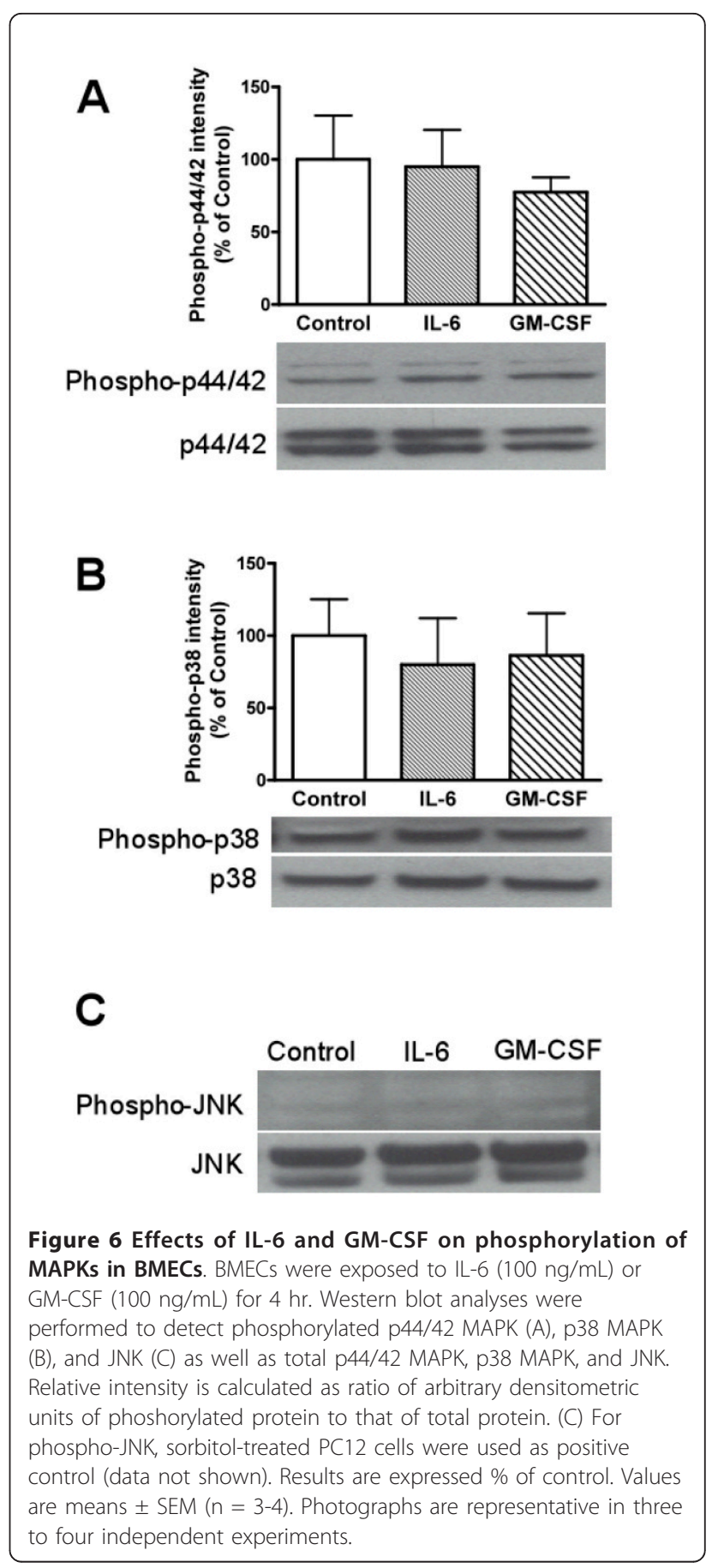

from BMEC by LPS mediated these effects. The presence of LPS and antibodies to IL-6 or GM-CSF in the luminal chamber attenuated LPS-enhanced HIV-1 transport across the BMEC monolayer without a change in TEER (Figure 1A and 1B). BMECs secrete IL-6 and GM-CSF into both the luminal and abluminal chambers [34]. To determine whether IL-6 and GM-CSF secreted by BMECs into the abluminal chamber are also involved 


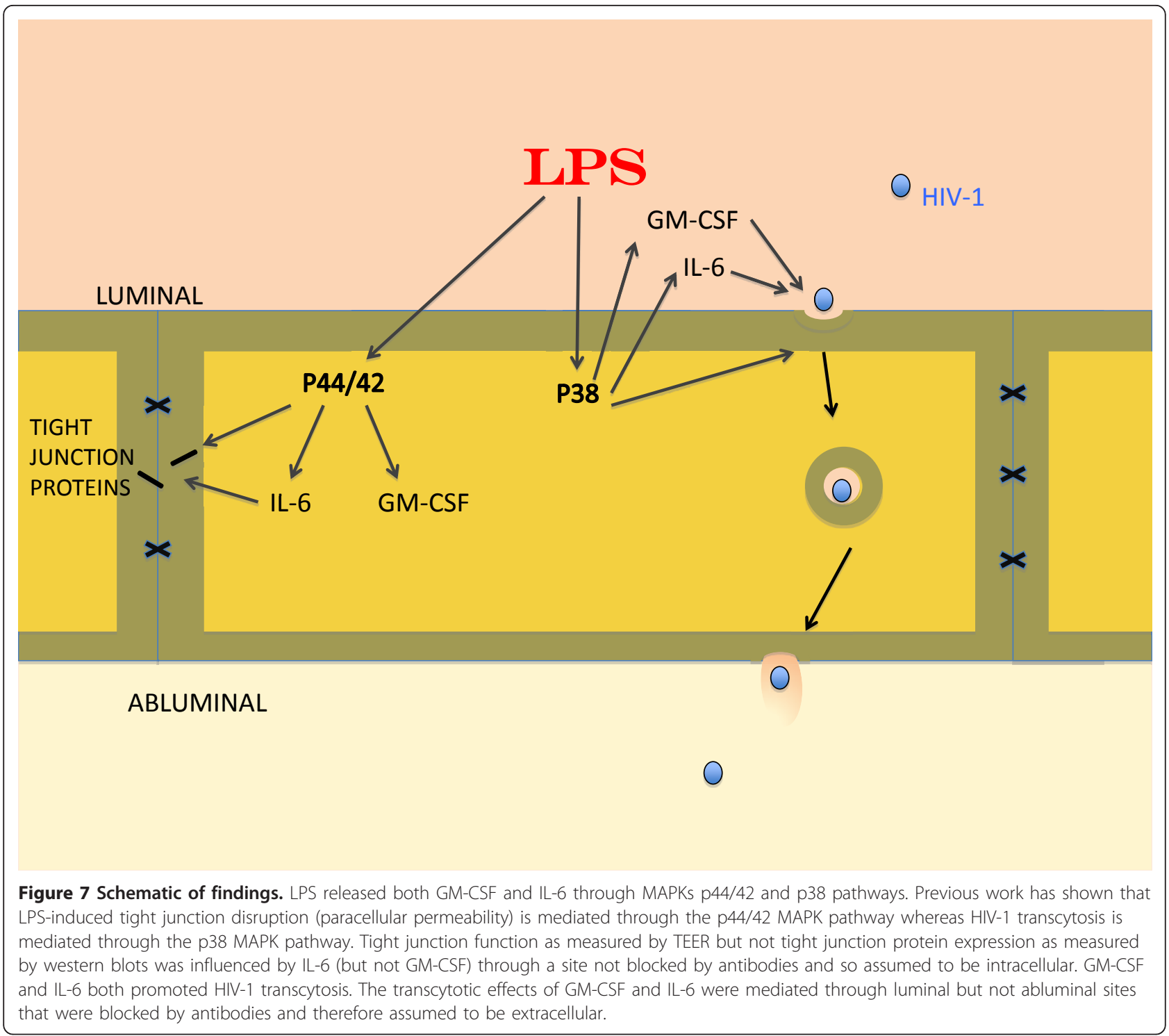

in the LPS-induced increase in HIV-1 transport, we added antibodies to IL- 6 or GM-CSF to the abluminal chamber. Neither antibody in the abluminal chamber inhibited the luminal LPS-induced changes in HIV-1 transport and TEER (Figure 1C and 1D). These results show that the IL- 6 and GM-CSF secreted by BMECs in response to luminal exposure to LPS act at the luminal, but not the abluminal, endothelial surface to increase the transcellular permeability of BMECs to HIV-1. Furthermore, the results suggest that the LPS-induced increase in the paracellular permeability of the BMEC monolayer as measured by TEER is not mediated by extracellular IL-6 and GM-CSF.

We further investigated this functional polarity by adding IL-6 and GM-CSF to the luminal or abluminal chamber. Polarity of other cytokine actions has been investigated. We previously found that BMECs show no functional polarity in the reduction of paracellular permeability by transforming growth factor (TGF)- $\beta 1$ [46]. That is, either luminal or abluminal TGF- $\beta 1$ has the same effect on the BBB paracellular permeability. In contrast, MCP-1 is only able to stimulate monocyte migration across BMECs when added to the abluminal surface [47]. In the current study, only luminal IL-6 increased HIV-1 transport and was 10-100 fold more potent than abluminal IL- 6 in decreasing TEER (Figure 2). Consistent with this, de Vries et al. reported that IL6 increased paracellular permeability of BMECs [48]. However, we found here that the IL-6-induced decrease in TEER was less than the LPS-induced decrease in TEER. Other soluble factors, such as other cytokines or chemokines, may be responsible for the remaining 
increase in the paracellular permeability induced by LPS. An IL-6-independent, P44/42-mediated phosphorylation of tight junction proteins may also be operational. The ability of IL-6 to decrease TEER but an inability of IL-6 antibody to block the effect of LPS on TEER suggests either that the LPS effect is not mediated through IL-6 or that IL- 6 acts at a site not available to antibodies, such as inside the cell. Abluminal IL-6 (100 ng/mL) did not alter HIV-1 permeability despite the decrease in TEER. This finding is consistent with IL-6 promoting a transcellular or transcytotic mechanism for HIV-1 passage across the BBB that is independent of the paracellular pathway.

Luminal GM-CSF at the concentration of $100 \mathrm{ng} / \mathrm{mL}$ increased HIV-1 transport, whereas abluminal GM-CSF did not. Neither luminal nor abluminal GM-CSF changed TEER (Figure 3). This result further supports the idea that HIV-1 penetration across the BBB is through the transcellular route rather than the paracellular route. In addition, these results may suggest that the receptors for IL-6 and GM-CSF that affect HIV-1 permeability are mainly localized to the luminal membrane of BMECs. Therefore, enhanced invasion of HIV-1 into the brain may be mediated by BMEC-derived cytokines secreted into blood or by blood-borne cytokines. Consistent with this, IL-6 in the blood compartment induces BBB dysfunction $[48,49]$. As summarized above, LPS, IL-6, and GM-CSF altered both HIV-1 permeability and TEER. The disparities discussed above between these two parameters of BBB function make it likely that they are separate events. Whereas the increased permeability to HIV-1 is likely mediated through transcytotic mechanisms, the decrease in TEER is caused by increased paracellular permeability resulting from altered tight junction function. LPS is known to alter the intensity and pattern of immunohistochemistry for the tight junction proteins claudin-5, ZO-1, and F-actin in BMECs $[31,33]$. We examined whether LPS, IL-6, and GM-CSF affected the expression of these tight junction proteins in our models (Figure 4). The luminal treatment with LPS, IL-6, or GM-CSF did not induce significant changes in the expression of tight junction proteins in BMECs. Therefore, under the conditions of our model, LPS and IL- 6 are likely increasing paracellular permeability of BMECs by altering tight junction function rather than expression of their proteins. For example, LPS and IL-6 may affect the localization of tight junction proteins in BMECs to increase the paracellular permeability.

Our previous work showed that LPS activated p44/42 MAPK and p38 MAPK in BMECs, and the activation of p38 MAPK resulted in the increase in HIV-1 transport [35]. The activation of the p38 MAPK pathway leads to the production and release of inflammatory cytokines
[50]. Considering our present results, we hypothesized that either (i) LPS induced the production of IL-6 and GM-CSF through MAPKs or (ii) IL-6 and GM-CSF activated MAPKs. First, we determined whether the LPSenhanced release of IL- 6 and GM-CSF was mediated by MAPK signaling pathways as shown by the experiments using U0126 (MEK1/2 inhibitor), SB203580 (p38 MAPK inhibitor), and SP600125 (JNK inhibitor) (Figure 5). U0126 and SB203580 inhibited the LPS-enhanced release of IL- 6 and GM-CSF by BMECs. In the SP600125-treated group, inhibitory effects were not detected. This is reasonable as an LPS-induced increase in the phosphorylation of JNK has not been detected [35]. These results indicated that LPS enhanced the release of IL- 6 and GM-CSF from BMECs through the phosphorylation of p44/42 MAPK and p38 MAPK. Thus, the transcellular pathway taken by free virus differs from the JNK dependent, CD40-mediated pathway used by infected monocytes to cross the BBB [3].

Next, we determined whether IL-6 and GM-CSF increased the phosphorylation of MAPKs. IL-6 and GMCSF did not increase the phosphorylation of $\mathrm{p} 44 / 42$ MAPK, p38 MAPK, or JNK (Figure 6). These results indicated that the IL-6- and GM-CSF-induced changes in the BMEC permeability for HIV-1 and paracellular permeability are downstream of the MAPK signaling pathways. Pathways downstream of the cytokines are likely COX-2 for IL-6-induced changes in TEER [48] and the JAK/STAT pathway for IL- 6 and GM-CSF [51,52] mediation of HIV-1 effects on immune cell migration [53]. Thus, IL-6 and GM-CSF likely increase HIV-1 transport across the BBB through other intracellular signaling pathways. As for the mechanisms by which LPS could increase HIV-1 transport across the $\mathrm{BBB}$, the following sequential events are proposed: (1) LPS activates p44/42 MAPK and p38 MAPK in BMECs; (2) this activation induces BMECs to release IL-6 and GM-CSF into the blood; (3) IL-6 and GM-CSF act at the luminal surface of the BMECs to enhance the transcellular transport of HIV-1 across the BBB.

In our previous study, we demonstrated that p38 MAPK mediated LPS-enhanced HIV-1 transport and p44/42 MAPK mediated the LPS-induced increase in paracellular permeability using each pathway inhibitor [35]. U0126, the p44/42 MAPK inhibitor, did not attenuate LPS-enhanced HIV-1 transport. Here, U0126 as well as SB203580 decreased the release of IL- 6 and GM-CSF (Figure 5). These findings suggest that the p38 MAPK signaling pathway directly leads to enhanced LPS-mediated transcellular transport of HIV-1.

In conclusion, we found that LPS potentiated the release of IL- 6 and GM-CSF by BMECs through the activation of p44/42 MAPK and p38 MAPK. In addition to the p38 MAPK pathway, IL-6 and GM-CSF released 
from BECs acted at the luminal but not the abluminal surface to enhance HIV-1 transcellular transport. The p44/42 MAPK pathway and IL-6 likely acted at an intracellular site to increase paracellular permeability. Thus, LPS effects on HIV-permeation and on paracellular permeability were mediated through different cellular pathways. These results suggest that the release of cytokines by BECs plays an important role in the invasion of HIV1 into the central nervous system. Preventing cytokine release by BECs through MAPK signaling pathways may be a therapeutic target in HIV-associated neurological dysfunction.

\begin{abstract}
Abbreviations
ANOVA: Analysis of variance; BBB: Blood-brain barrier; BEC: Brain endothelial cells; BMEC: Brain microvascular endothelial cells; CART: Combination antiretroviral therapy; GM-CSF: Granulocyte-macrophage colony-stimulating factor; HAART: Highly active antiretroviral therapy; HAD: HIV-1-associated dementia; HIV-1: Human immunodeficiency virus type 1; IL: Interleukin; IFN: Interferon; JNK: Jun kinase; LPS: Lipopolysaccharide; MAPK: Mitogen-activated protein kinase; MEK: MAPK kinase; $P_{\mathrm{e}}$ : Permeability coefficient; PVDF: Polyvinylidene difluoride; TEER: Transendothelial electrical resistance; TGF: Transforming growth factor; TLR: Toll-like receptor; TNF-a: Tumor necrosis factor-a.
\end{abstract}

\section{Acknowledgements}

The authors thank Dr. Maria A. Deli (Institute of Biophysics, Biological Research Centre of the Hungarian Academy of Sciences) for technical advice on primary BMEC culture and comments on this study. The virus was a kind gift the National Cancer Institute, National Institutes of Health. Funded in part with Federal funds from National Cancer Institute, National Institutes of Health, under Contract No. N01-CO-12400. The content of this publication does not necessarily reflect the views or policies of the Department of Health and Human Services, nor does mention of names, commercial products, or organization imply endorsement by the U.S. government. Supported by VA Merit Review (WAB), NIH R01NS050547 (WAB), and NIH R01AG029839 (WAB).

\section{Author details}

'Department of Pharmaceutical Care and Health Sciences, Faculty of Pharmaceutical Sciences, Fukuoka University, Fukuoka, Japan. ${ }^{2}$ Geriatric Research Educational and Clinical Center-St. Louis, St. Louis, MO, USA.

${ }^{3}$ Division of Geriatric Medicine, Department of Internal Medicine, Saint Louis University School of Medicine, St. Louis, MO, USA. ${ }^{4}$ Biology Department, Clarke University, Dubuque, IA, USA. ${ }^{5}$ Geriatric Research Educational and Clinical Center-Veterans Affairs Puget Sound Health Care System, Seattle, WA, USA. ${ }^{6}$ Division of Gerontology and Geriatric Medicine, Department of Internal Medicine, University of Washington, Seattle, WA, USA.

\section{Authors' contributions}

All authors contributed to experimental design in an interactive and synergistic fashion. Experiments were performed by SD and MAF-D. Writing was a joint effort with WAB overseeing and editing final draft. All authors have read and validated the final manuscript.

\section{Competing interests}

The authors declare that they have no competing interests.

Received: 18 August 2011 Accepted: 30 November 2011 Published: 30 November 2011

\section{References}

1. Gonzalez-Scarano F, Martin-Garcia J: The neuropathogenesis of AIDS. Nature Rev Immunol 2005, 5:69-81.
2. McArthur JC, Haughey N, Gartner S, Conant K, Pardo C, Nath A, Sacktor N: Human immunodeficiency virus-associated dementia: An evolving disease. J Neurovirol 2003, 9:205-221.

3. Eden A, Fuchs D, Hagberg L, Nilsson S, Spudich S, Svennerholm B, Price RW, Geisslen M: HIV-1 viral escape in cerebrospinal fluid of subjects on suppressive antiretroviral treatment. Journal of Infectious Diseases 2010, 202:1768-1769.

4. Banks WA, Akerstrom V, Kastin AJ: Adsorptive endocytosis mediates the passage of HIV-1 across the blood-brain barrier: evidence for a postinternalization coreceptor. Journal of Cell Science 1998, 111:533-540.

5. Banks WA, Freed EO, Wolf KM, Robinson SM, Franko M, Kumar VB: Transport of human immunodeficiency virus type 1 pseudoviruses across the blood-brain barrier: role of envelope proteins and adsorptive endocytosis. Journal of Virology 2001, 75:4681-4691.

6. Banks WA, Robinson SM, Wolf KM, Bess JW Jr, Arthur LO: Binding, internalization, and membrane incorporation of human immunodeficiency virus- 1 at the blood-brain barrier is differentially regulated. Neuroscience 2004, 128:143-153.

7. Nakaoke R, Ryerse JS, Niwa M, Banks WA: Human immunodeficiency virus type 1 transport across the in vitro mouse brain endothelial cell monolayer. Experimental Neurology 2005, 193:101-109.

8. Persidsky $Y$, Stins M, Way D, Witte MH, Weinand M, Kim KS, Bock P, Gendelman HE, Fiala M: A model for monocyte migration through the blood-brain barrier during HIV-1 encephalitis. The Journal of Immunology 1997, 158:3499-3510.

9. Liu NQ, Lossinsky AS, Popik W, Li X, Gujuluva C, Kriederman B, Roberts J, Pushkarsky $T$, Bukrinsky $M$, Witte $M$, et al: Human immunodeficiency virus type I enters brain microvascular endothelia by macropinocytosis dependent on lipid rafts and the mitogen-activated protein kinase signaling pathway. Journal of Virology 2002, 76:6689-6700.

10. Moses AV, Bloom FE, Pauza CD, Nelson JA: Human immunodeficiency virus infection of human brain capillary endothelial cells occurs via a CD4/galactosylceramide-independent mechanism. Proceedings of the National Academy of Sciences USA 1993, 90:10474-10478.

11. Davis LE, Hjelle BL, Miller VE, Palmer DL, Llewellyn AL, Merlin TL, Young SA, Mills RG, Wachsman W, Wiley CA: Early viral brain invasion in iatrogenic human immunodeficiency virus infection. Neurology 1992, 42:1736-1739.

12. Alonso K, Pontiggia P, Medenica R, Rizzo R: Cytokine patterns in adults with AIDS. Immunollnvest 1997, 26:341-350.

13. Gartner S: HIV infection and dementia. Science 2000, 287:602-604.

14. Hittinger G, Poggi C, Delbeke E, Profizi N, Lafeuillade A: Correlation between plasma levels of cytokines and HIV-1 RNA copy number in HIVinfected patients. Infection 1998, 26:100-103.

15. Fiala M, Looney DJ, Stins M, Way DD, Zhang L, Gan X, Chiappelli F, Schweitzer ES, Shapshak P, Weinand M, et al: TNF-alpha opens a paracellular route for HIV-1 invasion across the blood-brain barrier. Molecular Medicine 1997, 3:553-564.

16. Chaudhuri A, Duan F, Morsey B, Persidsky Y, Kanmogne GD: HIV-1 activates proinflammatory and interferon-inducible genes in human brain microvascular endothelial cells: putative mechanisms of blood-brain barrier dysfunction. J Cereb Blood Flow Metab 2007, 28:697-711.

17. Kanmogne GD, Primeaux C, Grammas P: HIV-1 gp120 proteins alter tight junction protein expression and brain endothelial cell permability: implications for the pathogenesis of HIV-associated dementia. Journal of Neuropathology and Experimental Neurology 2005, 64:498-505.

18. Andras IE, Pu H, Deli MA, Nath A, Hennig B, Toborek M: HIV-1 Tat protein alters tight junction protein expression and distribution in cultured brain endothelial cells. Journal of Neuroscience Research 2003, 74:255-265.

19. Pu H, Tian J, Flora G, Lee YW, Nath A, Hennig B, Toborek M: HIV-1 Tat protein upregulates inflammatory mediators and induces monocyte invasion into the brain. Molecular and Cellular Neurosciences 2003, 24:224-237.

20. Andras I, Pu H, Tian J, Deli MA, Nath A, Hennig B, Toborek M: Signaling mechanisms of HIV-1 Tat-induced alterations of claudin-5 expression in brain endothelial cells. J Cereb Blood Flow Metab 2005, 25:1159-1170.

21. Brenchley JM, Price DA, Schacker TW, Asher TE, Silvestri G, Rao S, Kazzaz Z, Bornstein E, Lambotte O, Altmann D, et al: Microbial translocation is a cause of systemic immune activation in chronic HIV injection. Nature Medicine 2006, 12:1365-1371.

22. Blanchard A, Montagnier L, Gougeon ML: Influence of microbial infections on the progression of HIV disease. Trends Microbiol 1997, 5:326-331. 
23. Hesse DG, Tracey KJ, Fong Y, Manogue KR, Palladino MA, Cerami A, Shires GT, Lowry SF: Cytokine appearance in human endotoxemia and primate bacteremia. Surg Gynecol Obstet 1998, 166:147-153.

24. Martich GD, Boujoukos AJ, Suffredini AF: Response of man to endotoxin. Immunobiology 1993, 187:403-416.

25. Shalaby MR, Waage A, Aarden L, Espevik T: Endotoxin, tumor necrosis factor-alpha and interleukin-1 induce interleukin 6 production in vivo. Clin Immunol Immunopath 1989, 53:488-498.

26. Banks WA, Kastin AJ, Brennan JM, Vallance KL: Adsorptive endocytosis of HIV-1 gp120 by blood-brain barrier is enhanced by lipopolysaccharide. Experimental Neurology 1999, 156:165-171.

27. Singh AK, Yiang Y: How does peripheral lipopolysaccharide induce gene expression in the brain of rats? Toxicology 2004, 201:197-207.

28. Deli MA, Abraham CR, Kataoka Y, Niwa M: Permeability studies on in vitro blood-brain barrier models: physiology, pathology, and pharmacology. Cellular and Molecular Neurobiology 2005, 25:59-127.

29. Tunkel AR, Rosser SW, Hansen EJ, Scheld WM: Blood-brain barrier alterations in bacterial meningitis: development of an in vitro model and observations on the effects of lipopolysaccharide. In Vitro Cellular \& Developmental Biology 1991, 27A:113-120.

30. De Vries HE, Blom-Roosemalen MCM, De Boer AG, van Berkel TJ, Breimer DD, Kuiper J: Effect of endotoxin on permeability of bovine cerebral endothelial cell layers in vitro. Journal of Pharmacology and Experimental Therapeutics 1996, 277:1418-1423.

31. Descamps L, Coisne C, Dehouck B, Cecchelli R, Torpier G: Protective effect of glial cells against lipopolysaccharide-mediated blood-brain barrier injury. Glia 2003, 42:46-58.

32. Boveri M, Kinsner A, Berezowski V, Lenfant AM, Draing C, Cecchelli R, Dehouck MP, Hartung T, Prieto P, Bal-Price A: Highly purified lipoteichoic acid from gram-positive bacteria induced in vitro blood-brain barrier disruption through glia activation: role of proinflammatory cytokines and nitric oxide. Neuroscience 2006, 137:1193-1209.

33. Veszelka S, Pasztoi M, Farkas AE, Krizbai I, Ngo TK, Niwa M, Abraham CS, Deli MA: Pentosan polysulfate protects brain endothelial cells against bacterial lipopolysaccharide-induced damages. Nerurochem Int 2007, 50:219-228.

34. Verma S, Nakaoke R, Dohgu S, Banks WA: Release of cytokines by brain endothelial cells: a polarized response to lipopolysaccharide. Brain, Behavior, and Immunity 2006, 20:449-455.

35. Dohgu S, Banks WA: Lipopolysaccharide-enhanced transcellular transport of HIV-1 across the blood-brain barrier is medited by the p38 mitogenactivated protein kinase pathway. Experimental Neurology 2008, 210:740-749.

36. Rossio JL, Esser MT, Suryanarayana K, Schneider DK, Bess JW Jr, Vasquez GM, Wiltrout TA, Chertova E, Grimes MK, Sattentau Q, et al: Inactivation of human immunodeficiency virus type 1 infectivity with preservation of conformational and functional integrity of virion surface proteins. Journal of Virology 1998, 72:7992-8001.

37. Frost EH: Radioactive labelling of viruses: an iodination preserving biological properties. JGenVirol 1977, 35:181-185.

38. Montelaro RC, Rueckert RR: On the use of chloramine-T to iodinate specifically the surface proteins of intact enveloped viruses. JGenVirol 1975, 29:127-131.

39. Szabo CA, Deli MA, Ngo TKD, Joo F: Production of pure primary rat cerebral endothelial cell culture: a comparison of different methods. Neurobiology 1997, 5:1-16.

40. Perriere N, Demeuse P, Garcia E, Regina A, Debray M, Andreux JP, Couvreur P, Scherrmann JM, Temsamani J, Couraud PO, et al: Puromycinbased purification of rat brain capillary endothelial cell cultures. $J$ Neurochem 2005, 93:279-289.

41. Dehouck MP, Jolliet-Riant P, Bree F, Fruchart JC, Cecchelli R, Tillement JP: Drug transfer across the blood-brain barrier: Correlation between in vitro and in vivo models. J Neurochem 1992, 58:1790-1797.

42. Waage A, Bakke O: Glucocorticoids suppress the production of tumor necrosis factor by lipopolysaccharide-stimulated human monocytes. Immunology 1988, 63:299-302.

43. Hoheisel D, Nits T, Franke H, Wegener J, Hakvoort A, Tilling T, Galla HJ: Hydrocortisone reinforces the blood-brain barrier properties in a serum free cell culture system. Biochemical and Biophysical Research Communications 1998, 217:312-315.
44. Mayhan WG, Heistad DD: Permeability of blood-brain barrier to various sized molecules. Am J Physiology 1985, 248:H712-H718.

45. Chou S, Dix RD: Viral infections and the blood-brain barrier. In Implications of the Blood-Brain Barrier and Its Manipulation, Volume 2: Clinical Aspects. Edited by: Neuwelt EA. New York: Plenum Publishing Corporation; 1989:449-468.

46. Dohgu S, Takata F, Yamauchi A, Nakagawa S, Egawa T, Naito M, Tsuruo T, Sawada Y, Niwa M, Kataoka Y: Brain pericytes contribute to the upregulation and maintenance of blood-brain barrier functions through transforming growth factor-beta production. Brain Res 2005, 1038:208-215.

47. Andjelkovic AV, Zochowski MR, Morgan F, Pachter JS: Qualitative and quantitative analysis of monocyte transendothelial migration by confocal microscopy and three-dimensional image reconstruction. In Vitro Cellular \& Developmental BiologyAnimal 2001, 37:111-120.

48. de Vries HE, Blom-Roosemalen MCM, van Oosten M, de Boer AG, van Berkel TJC, Breimer DD, Kuiper J: The influence of cytokines on the integrity of the blood-brain barrier. Journal of Neuroimmunology 1996, 64:37-43.

49. Farkas G, Marton J, Nagy Z, Mandi Y, Takacs T, Deli MA, Abraham CS: Experimental acute pancreatitis results in increased blood-brain barrier permeability in the rat: a potential role for tumor necrosis factor and interleukin 6. Neurosci Lett 1998, 242:147-150.

50. Dong C, Davis RJ, Flavell RA: MAP kinase in the immune response. Annual Review of Immunology 2002, 20:55-72.

51. Heinrich PC, Behrmann I, Haan S, Hermanns HM, Muller-Newen G, Schaper F: Principles of interleukin (IL)-6 cytokine signaling and its regulation. Biochem J 2003, 374:1-20.

52. Al-Shami A, Mahanna W, Naccache PH: Granulocyte-macrophage colonystimulating factor-activated signaling pathways in human neutrophils. $J$ Biol Chem 1998, 273:1058-1063.

53. Anathbandhu C, Yang B, Gendelman HE, Persidsky Y, Kanmogne GD: STAT1 signaling modulates HIV-1-induced inflammatory responses and leukocyte transmigration across the blood-brain barrier. Blood 2007, 111:2062-2072.

doi:10.1186/1742-2094-8-167

Cite this article as: Dohgu et al.: Lipopolysaccharide-enhanced transcellular transport of HIV-1 across the blood-brain barrier is mediated by luminal microvessel IL- 6 and GM-CSF. Journal of Neuroinflammation $20118: 167$

\section{Submit your next manuscript to BioMed Central and take full advantage of:}

- Convenient online submission

- Thorough peer review

- No space constraints or color figure charges

- Immediate publication on acceptance

- Inclusion in PubMed, CAS, Scopus and Google Scholar

- Research which is freely available for redistribution

Submit your manuscript at www.biomedcentral.com/submit
C) Biomed Central 